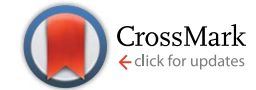

Cite this: RSC Adv., 2017, 7, 5800

Received 27th October 2016 Accepted 26th December 2016

DOI: $10.1039 / c 6 r a 25900 f$

www.rsc.org/advances

\section{PdCu alloy nanodendrites with tunable composition as highly active electrocatalysts for methanol oxidation $\uparrow$}

\author{
Yaling Xiong, $\dot{t}^{\mathrm{a}}$ Wenying Ye, $\dot{t}^{\mathrm{a}}$ Wenlong Chen, $t^{\mathrm{b}}$ Yiwen Wu, ${ }^{\mathrm{a}}$ Qingfeng $\mathrm{Xu},{ }^{\mathrm{a}}$ \\ Yucong Yan, ${ }^{a}$ Hui Zhang, *a Jianbo Wu*b and Deren Yang*a
}

Metal nanodendrites composed of highly branched arms have received great attention as electrocatalysts owing to their reasonably large surface area and the potential existence of low-coordinated sites in high densities. Although significant progress has been made in the synthesis of bimetallic nanodendrites, few works involve a system consisting of $\mathrm{Pd}$ and $\mathrm{Cu}$, particularly in the case of alloyed nanodendrites. Here, we report a facile and powerful approach for the synthesis of $\mathrm{PdCu}$ alloy nanodendrites with tunable composition through varying the molar ratio of the $\mathrm{Pd}$ and $\mathrm{Cu}$ salt precursors. The key to achieving $\mathrm{PdCu}$ alloy nanodendrites is the use of $\mathrm{W}(\mathrm{CO})_{6}$, which serves as a strong reducing agent. In addition, variation in the molar ratio of the precursors, from $\mathrm{Pd}$ rich to $\mathrm{Cu}$ rich, leads to shape evolution of the $\mathrm{PdCu}$ alloy, moving from a polyhedral to a dendritic nanostructure. This result indicates that galvanic replacement between a Cu rich alloy and a $\mathrm{Pd}$ precursor also plays an important role in the formation of $\mathrm{PdCu}$ alloy nanodendrites. When used as electrocatalysts for the methanol oxidation reaction (MOR), PdCu alloy nanodendrites exhibit remarkably enhanced catalytic properties relative to commercial $\mathrm{Pd} / \mathrm{C}$. Specifically, $\mathrm{Pd}_{35} \mathrm{Cu}_{65}$ alloy nanodendrites show the highest specific activity and mass activity for the MOR, 9.3 and 7.6 times higher than that of commercial $\mathrm{Pd} / \mathrm{C}$, respectively. This enhancement can be attributed to their dendritic structure and a possible bifunctional mechanism between $\mathrm{Pd}$ and $\mathrm{Cu}$.

\section{Introduction}

Proton exchange membrane fuel cells (PEMFCs) provide a direct way to convert the chemical energy of various fuels (e.g., hydrogen, methanol, and formic acid) into electricity at low temperature without combustion that has several features, including high energy conversion efficiency, high power density, and low pollutant emission. ${ }^{\mathbf{1}, 2}$ These advantages make PEMFCs an attractive candidate to be a clean and sustainable energy solution in both electric vehicles and portable electronics. ${ }^{3,4}$ Among various types of fuel cells, direct methanol fuel cells (DMFCs), operated through the direct use of methanol as an electrochemically active fuel at the anode, are of particular interest since they can further circumvent the problems of

${ }^{a}$ State Key Laboratory of Silicon Materials, School of Materials Science \& Engineering, Cyrus Tang Center for Sensor Materials and Applications, Zhejiang University, Hangzhou, Zhejiang 310027, People's Republic of China. E-mail: msezhanghui@zju. edu.cn; mseyang@zju.edu.cn

${ }^{b}$ State Key Laboratory of Metal Matrix Composites, School of Materials Science and Engineering, Shanghai Jiao Tong University, 800 Dongchuan Rd, Shanghai, 200240, People's Republic of China. E-mail: jianbowu@sjtu.edu.cn

$\dagger$ Electronic supplementary information (ESI) available. See DOI: 10.1039/c6ra25900f

\$ These authors contributed equally to this work. hydrogen storage and transportation in PEMFCs. ${ }^{5-7}$ Up to now, Pt-based nanoparticles have been proven to be the most effective monometallic catalyst for the methanol oxidation reaction (MOR) at the anode in DMFCs, because Pt sites are remarkably active for methanol adsorption and dissociation. ${ }^{\mathbf{8 9}}$ However, the rapidly increasing price and severely limited reserves of this metal are major obstacles to its commercial application in DMFCs. ${ }^{10-12}$ In general, there are two main strategies to address the aforementioned issues. One is to enhance the catalytic performance and utility efficiency of Pt through size and shape control, as well as structure and composition design. ${ }^{\mathbf{1 3 - 2 0}}$ The other is the pursuance of a promising substitute for Pt as the catalyst in DMFCs without compromising on the relevant properties. Pd is believed to be a suitable replacement for Pt due to its excellent potential for improving catalytic properties towards the MOR in alkaline media, and it is at least 50 times more abundant than Pt. ${ }^{21-23}$

Recently, introducing a second metal (e.g., $\mathrm{Au}, \mathrm{Ag}, \mathrm{Ni}$ or $\mathrm{Cu}$ ) to form Pd-based bimetallic nanostructures has been considered as an effective strategy to improve catalytic performance, because of bifunctional mechanisms and/or ligand effects. ${ }^{24-28}$ As a relatively less expensive and earth-abundant metal, $\mathrm{Cu}$ is a particularly promising candidate for generating PdCu bimetallic-based catalysts. ${ }^{29,30}$ In addition to composition 
variation, tuning the shape and/or structure of PdCu-based catalysts is also of great importance in enhancing their catalytic properties toward the MOR, due to its well-known structural sensitivity. ${ }^{31-34}$ As such, strong efforts have been employed towards developing the shape-controlled synthesis of $\mathrm{PdCu}$ bimetallic nanocrystals with improved performance. ${ }^{35-38}$ Among various shapes, catalysts with a dendritic nanostructure are expected to be promising because of attractive structural features, such as porosity, high surface area, an interconnected nanostructure, and excellent electrical connectivity, which have received unprecedented interest in catalysis. ${ }^{39-41}$ For example, Xia and co-workers demonstrated the synthesis of PdPt bimetallic nanodendrites with substantially enhanced catalytic properties towards the oxygen reduction reaction relative to commercial Pt/C via seeded growth. ${ }^{42}$ In a recent study, we reported the synthesis of RhPd nanodendrites, through a coreduction reaction, as highly active and durable electrocatalysts for the oxygen reduction reaction. ${ }^{43}$ Both of these dendritic structures were formed through diffusion-limited aggregation owing to high supersaturation achieved in the initial stage of the reaction. Although significant progress has been made in the synthesis of bimetallic nanodendrites, producing PdCu bimetallic nanodendrites has met with limited success, probably due to the difficulty in achieving high supersaturation during the reaction, arising from the low redox potential of $\mathrm{Cu}^{2+} / \mathrm{Cu}$.

Here, we report a facile, one-step approach for the synthesis of PdCu alloy nanodendrites with controllable composition in benzyl alcohol, with $\mathrm{W}(\mathrm{CO})_{6}$ as a strong reducing agent. $\mathrm{PdCu}$ alloy nanodendrites exhibit substantially enhanced catalytic properties towards the MOR in alkaline media relative to commercial Pd/C.

\section{Experimental section}

\section{Chemicals and materials}

Copper(II) acetylacetonate $\left(\mathrm{Cu}(\mathrm{acac})_{2}, 99 \%\right)$, palladium(II) acetylacetonate $\left(\mathrm{Pd}(\mathrm{acac})_{2}, 99 \%\right)$, polyvinyl pyrrolidone (PVP, MW $\approx 29000$ ), and tungsten hexacarbonyl $\left(\mathrm{W}(\mathrm{CO})_{6}, 97 \%\right)$ were purchased from Sigma-Aldrich. Commercial Pd/C (10 wt\%) was purchased from Alfa Aesar. Benzyl alcohol (AR), ethanol (AR), and acetone (AR) were purchased from Sinopharm Chemical Reagent Co., Ltd. All chemicals were used without further purification.

\section{Synthesis of PdCu alloy nanodendrites}

In a standard procedure, $13 \mathrm{mg}$ of $\mathrm{Cu}(\mathrm{acac})_{2}, 15 \mathrm{mg}$ of $\mathrm{Pd}(\mathrm{acac})_{2}$, and $50 \mathrm{mg}$ of PVP were dissolved in $10 \mathrm{~mL}$ of benzyl alcohol under magnetic stirring at room temperature for $1 \mathrm{~h}$. The resulting homogeneous solution was transferred into a $25 \mathrm{~mL}$ round-bottom flask. After that, $100 \mathrm{mg}$ of $\mathrm{W}(\mathrm{CO})_{6}$ was added into the flask under an $\mathrm{Ar}$ atmosphere. The reaction mixture was then sealed and heated at $140{ }^{\circ} \mathrm{C}$ for $2 \mathrm{~h}$ before it was cooled down to room temperature. Finally, the solution was centrifuged at $10000 \mathrm{rpm}$ and washed three times with ethanol before characterization.

\section{Morphological, structural, and compositional characterization}

The obtained samples were characterized using X-ray powder diffraction (XRD), using a Rigaku D/max-ga X-ray diffractometer with graphite monochromatized $\mathrm{Cu} \mathrm{K} \alpha$ radiation $(\lambda=1.54178$ A). Transmission electron microscopy (TEM) images were taken using a HITACHI HT-7700 microscope operated at $100 \mathrm{kV}$. Highresolution transmission electron microscopy (HRTEM), highangle annular dark-field scanning TEM (HAADF-STEM), and energy dispersive X-ray (EDX) mapping analyses were performed using an FEI Tecnai G2 F20 microscope operated at $200 \mathrm{kV}$. The percentages of $\mathrm{Pd}$ and $\mathrm{Cu}$ in the samples were determined using inductively coupled plasma atomic emission spectrometry (ICPAES, IRIS Intrepid II XSP, TJA Co., USA). Thermogravimetric analysis (TGA) was performed with a thermogravimetric analyzer (SDT Q600). The temperature was monitored from room temperature to $800{ }^{\circ} \mathrm{C}$, with a scan rate of $10{ }^{\circ} \mathrm{C} \mathrm{min} \mathrm{m}^{-1}$.

\section{Preparation of carbon-supported catalysts}

In a standard preparation, carbon black (Vulcan XC72) was dispersed in ethanol and sonicated for $30 \mathrm{~min}$. A designated amount of $\mathrm{PdCu}$ particles was added to this dispersion, with a $\mathrm{PdCu} / \mathrm{C}$ mass ratio of $20: 80$. This mixture was further sonicated for $10 \mathrm{~min}$ and stirred for $24 \mathrm{~h}$. After that, the resultant solids were precipitated out using centrifugation and washed three times with ethanol.

\section{Electrochemical measurements}

A three-electrode cell with an electrochemical workstation (CHI $760 \mathrm{E}$ ) was used to measure the electrochemical performance of the $\mathrm{PdCu} / \mathrm{C}$ catalysts, including the commercial Pd/C. A glassycarbon rotating disk electrode (RDE, Pine Research Instrumentation, United States) was used as the working electrode (area: $\left.\sim 0.196 \mathrm{~cm}^{2}\right)$. An Ag/AgCl electrode and a Pt mesh $\left(1 \times 1 \mathrm{~cm}^{2}\right)$ connected to a Pt wire were used as the reference and counter electrodes, respectively. To make a catalyst ink, $5 \mathrm{mg}$ of $\mathrm{PdCu} / \mathrm{C}$ catalyst was dispersed in $10 \mathrm{~mL}$ of mixed solvent and sonicated for $10 \mathrm{~min}$. The solvent contained a mixture of de-ionized water, isopropanol, and 5\% Nafion 117 solution at the volumetric ratio of $8: 2: 0.05$. After that, $60 \mu \mathrm{L}$ of the catalyst ink was added onto the RDE and dried under air flow for $30 \mathrm{~min}$ to make the working electrode. The electrochemical active surface area (ECSA) was determined from the cyclic voltammogram (CV) curves, calculating the amount of charge through integrating the hydrogen desorption region after double layer correction. The CV measurements were carried out in Ar-saturated 0.1 M $\mathrm{KOH}$ solution at room temperature with a scan rate of $50 \mathrm{mV} \mathrm{s}^{-1}$, and before the test Ar purging was conducted for $30 \mathrm{~min}$. For the electrooxidation of methanol, $\mathrm{CV}$ curves were recorded in an Arpurged $0.1 \mathrm{M} \mathrm{KOH} / 0.5 \mathrm{M} \mathrm{CH}_{3} \mathrm{OH}$ solution at a sweep rate of $50 \mathrm{mV} \mathrm{s}^{-1}$ in the range of $0.05 \mathrm{~V}$ to $1.2 \mathrm{~V}$ ( $v s$. RHE).

\section{Results and discussion}

PdCu alloy nanodendrites were synthesized via the co-reduction of Pd and $\mathrm{Cu}$ salt precursors with $\mathrm{W}(\mathrm{CO})_{6}$ in benzyl alcohol at 
$140{ }^{\circ}$ C. Fig. 1 shows TEM, HRTEM, HAADF-STEM and EDX mapping images of the $\mathrm{PdCu}$ alloy nanodendrites, prepared using the aforementioned approach with a $\mathrm{Pd} / \mathrm{Cu}$ molar ratio of $1: 1$ in the synthesis (i.e., the standard procedure). As demonstrated in the TEM images in Fig. $1 \mathrm{~A}$ and B, most of the nanocrystals were observed to have a dendritic structure with a flower-like shape. Careful observation shows that the dendrite is composed of numerous small particles of less than $10 \mathrm{~nm}$ in size. The overall size of the nanodendrite is $\sim 30 \mathrm{~nm}$. Fig. 1C shows a typical HRTEM image of an individual nanodendrite. It is clear that the nanodendrite is a polycrystal, consisting of single-crystalline particles (marked with circles). The fringes with a lattice spacing of $2.17 \AA$ can be indexed to the $\{111\}$ planes of face-centered cubic (fcc) Pd and/or Cu. The elemental distribution of the nanodendrite is determined using EDX mapping analysis (Fig. 1D). It is indicated that both $\mathrm{Pd}$ and $\mathrm{Cu}$ are distributed evenly throughout each $\mathrm{PdCu}$ nanodendrite, confirming an alloy structure. Moreover, the compositions of the $\mathrm{PdCu}$ nanodendrites were quantitatively measured using inductively coupled plasma atomic emission spectrometry (ICPAES, Table S1 $\dagger$ ). The $\mathrm{Pd} / \mathrm{Cu}$ atomic ratio of these nanodendrites was about 0.91 : 1 (i.e., $\mathrm{Pd}_{48} \mathrm{Cu}_{52}$ ), which is consistent with the molar ratio of $\mathrm{Pd}$ and $\mathrm{Cu}$ salt precursors used in the synthesis.

The compositions of the $\mathrm{PdCu}$ alloy nanostructures were readily tuned by varying the amounts of $\mathrm{Pd}$ and $\mathrm{Cu}$ salt precursors supplied in the synthesis. On the basis of ICP-AES analysis, $\mathrm{Pd}_{77} \mathrm{Cu}_{23}, \mathrm{Pd}_{65} \mathrm{Cu}_{35}, \mathrm{Pd}_{43} \mathrm{Cu}_{57}$, and $\mathrm{Pd}_{35} \mathrm{Cu}_{65}$ alloy nanostructures were obtained when the molar ratio of the $\mathrm{Pd}$ and $\mathrm{Cu}$ precursors was varied from $4: 1$ to $2: 1,2: 3$, and $1: 3$ (Table S1 $\dagger$ ). Fig. 2 shows XRD patterns of these PdCu samples with different compositions, together with a Pd/C sample. From the XRD patterns, all the PdCu samples clearly show three welldefined diffraction peaks, corresponding to the (111), (200), and (220) planes of a single fcc lattice, suggesting the formation of

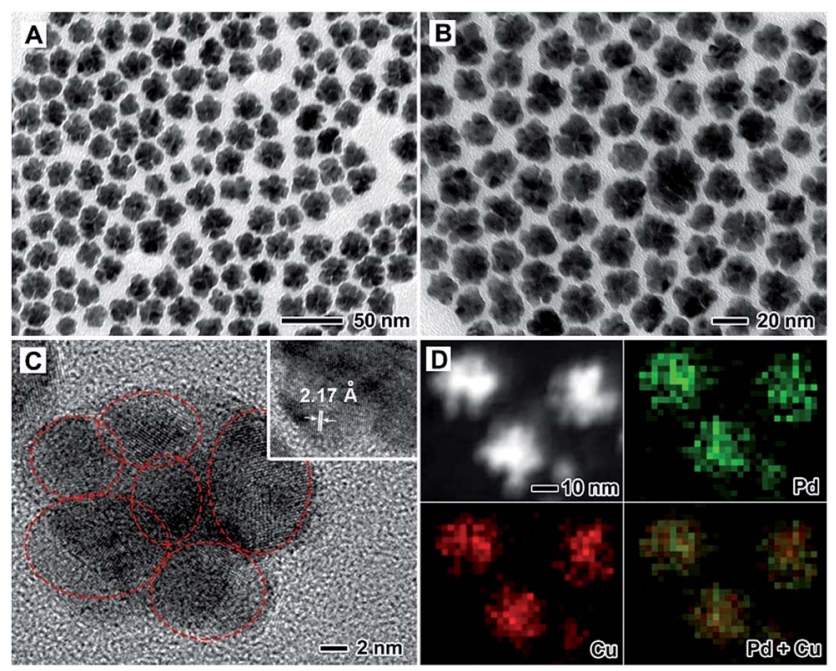

Fig. 1 (A, B) TEM, (C) HRTEM, and (D) HAADF-STEM-EDX mapping images of $\mathrm{PdCu}$ alloy nanodendrites prepared using the standard procedure, with a $\mathrm{Pd} / \mathrm{Cu}$ molar ratio of $1: 1$ used in the synthesis. The inset of $(C)$ corresponds to the HRTEM image at a higher magnification. The green and red correspond to Pd and Cu elements, respectively.

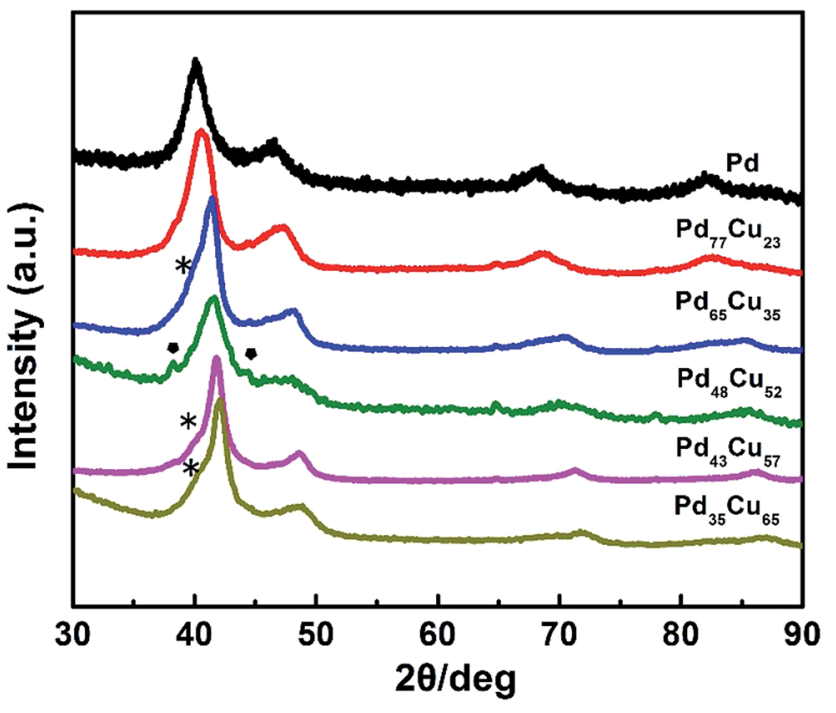

Fig. 2 XRD patterns of PdCu alloy nanostructures with different compositions, including commercial Pd/C.

an alloy structure. The diffraction peaks gradually shift to higher values of $2 \theta$ upon increasing the amount of $\mathrm{Cu}$ component, due to a decreased lattice constant arising from the smaller diameter of $\mathrm{Cu}$ atoms relative to $\mathrm{Pd}$ atoms. However, careful observation indicates that the $\{111\}$ peaks are asymmetric and small diffraction peaks associated with $\mathrm{Cu}_{2} \mathrm{O}$ (marked by $\bullet$ ) or pure Pd (marked by *) can be resolved. Exposure to oxygen and slight phase separation could be responsible for the impurities of $\mathrm{Cu}_{2} \mathrm{O}$ and pure Pd. In addition, we found that the molar ratio of $\mathrm{Pd}$ and $\mathrm{Cu}$ salt precursors has a great influence on the morphology of the PdCu alloy nanostructures. Fig. 3 shows typical TEM images of PdCu alloy nanostructures with different compositions. It is clear that the shape of the $\mathrm{PdCu}$ alloy nanostructures evolves from polyhedral to nanodendrite upon increasing the $\mathrm{Cu}$ content (Fig. 3A-D). The $\mathrm{Cu}-$ rich samples also prefer to adopt a dendritic shape with longer branched arms.

In order to decipher the growth mechanism of the $\mathrm{PdCu}$ nanodendrites, a series of samples obtained at different stages during the synthesis of $\mathrm{Pd}_{48} \mathrm{Cu}_{52}$ nanodendrites (i.e., the standard procedure) were collected for TEM and ICP-AES analyses. In the initial stage of the reaction $(t=2.5 \mathrm{~min})$, a Pd-rich sample with a composition of $\mathrm{Pd}_{83} \mathrm{Cu}_{17}$ (see Fig. S1†) was generated due to the easier reduction of the $\mathrm{Pd}$ precursor relative to the $\mathrm{Cu}$ precursor, arising from the larger redox potential of $\mathrm{Pd}^{2+} / \mathrm{Pd}$ (0.951 V versus $\mathrm{RHE}$ ) compared to $\mathrm{Cu}^{2+} / \mathrm{Cu}(0.342 \mathrm{~V}$ versus $\mathrm{RHE})$. However, the morphology of the product at this time cannot be revealed using TEM due to the difficulty in precipitating the sample via centrifugation, as a result of the very small particle size. As the reaction continued to $t=5 \mathrm{~min}$, numerous small PdCu particles were generated (Fig. 4A). From ICP-AES analysis shown in Fig. $\mathrm{S} 1, \uparrow$ these particles are composed of $\mathrm{Pd}_{55} \mathrm{Cu}_{45}$ with a remarkable increase in the $\mathrm{Cu}$ content. As is well-known, $\mathrm{Cu}(\mathrm{acac})_{2}$ is very difficult to directly reduce to $\mathrm{Cu}$ due to the small redox potential of $\mathrm{Cu}^{2+} / \mathrm{Cu}$, resulting in the low $\mathrm{Cu}$ 


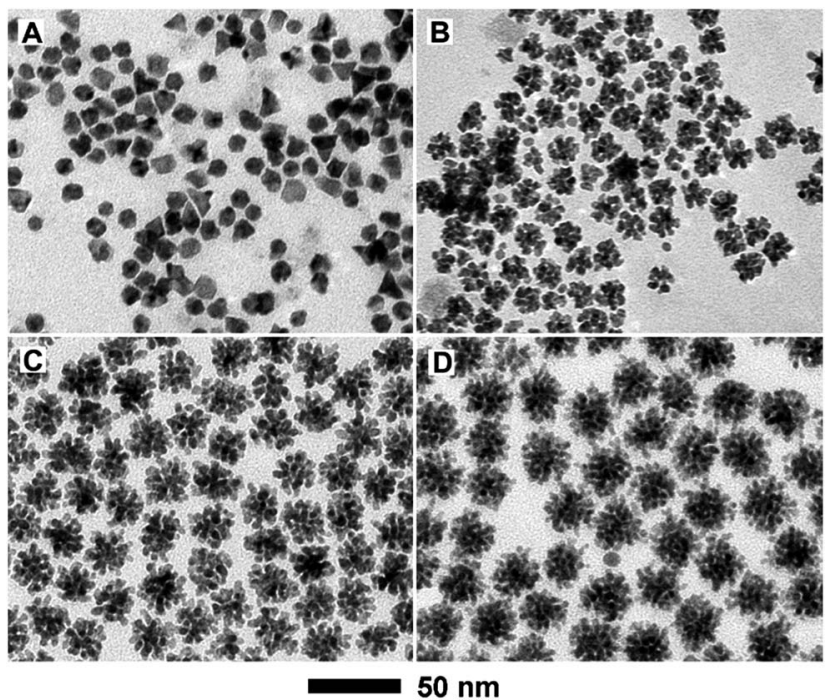

Fig. 3 TEM images of $\mathrm{PdCu}$ alloy nanostructures with different compositions prepared using the standard procedure, except with a different molar ratio of $\mathrm{Pd}$ and $\mathrm{Cu}$ salt precursors supplied in the synthesis: (A) $4: 1$; (B) $2: 1$; (C) $2: 3$; and (D) $1: 3$.

content of the final product. For a system involving Pd and $\mathrm{Cu}$, however, underpotential deposition (UPD) and galvanic replacement usually happen during nanocrystal growth, which was also observed in the synthesis of PdCu tripods. ${ }^{36} \mathrm{As}$ a result, the initially formed Pd-rich particles induce the reduction of $\mathrm{Cu}^{2+}$ ions by taking advantage of $\mathrm{Cu}$ UPD, resulting in an increase in $\mathrm{Cu}$ content in the $\mathrm{PdCu}$ alloy. When the reaction proceeded to $t=10 \mathrm{~min}$, dendritic structures with a composition of $\mathrm{Pd}_{54} \mathrm{Cu}_{46}$ were formed (Fig. 4B). Similar to our previous results for the synthesis of PtCu nanodendrites, ${ }^{44}$ the generation of $\mathrm{PdCu}$ nanodendrites can be attributed to galvanic replacement between the initially formed PdCu alloy with high

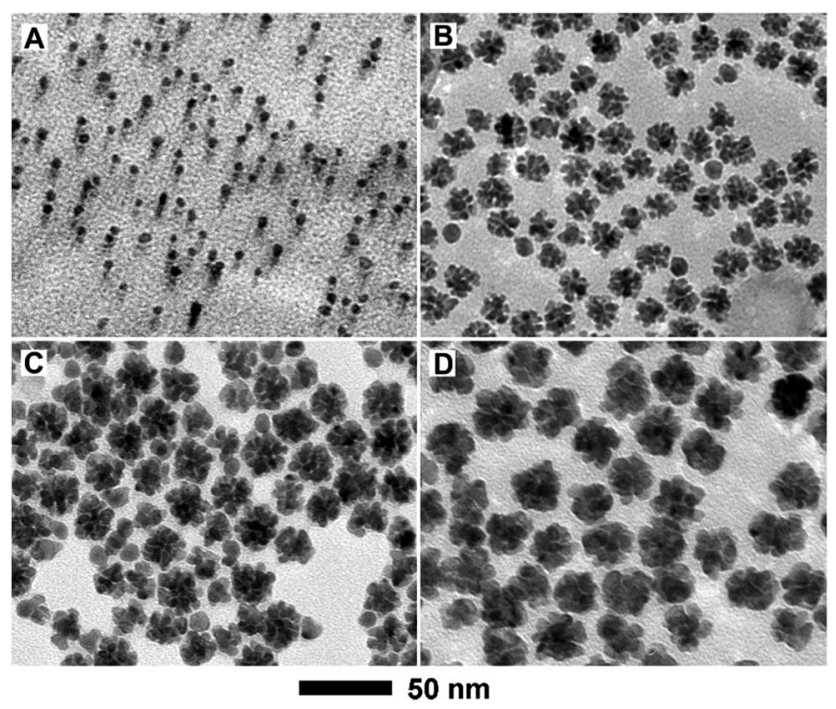

Fig. 4 TEM images of $\mathrm{PdCu}$ nanostructures prepared using the standard procedure, except with different periods of reaction time: (A) 5; (B) 10; (C) 30; and (D) $60 \mathrm{~min}$.
$\mathrm{Cu}$ content and $\mathrm{Pd}^{2+}$ ions in solution, which generally results in dendritic structures..$^{45}$ This demonstration is also supported by the morphology variation between different $\mathrm{Pd} / \mathrm{Cu}$ compositions, in which the $\mathrm{Cu}$-rich samples facilitate galvanic replacement and thus prefer to adopt a dendritic shape. With an extension of the reaction time (e.g., 30 and $60 \mathrm{~min}$ ), the branches of the nanodendrites grew up, resulting in the formation of nanodendrites of high-quality (Fig. 4C and D). The composition of the PdCu nanodendrites is an atomic ratio of about 1 (Fig. S1 $\dagger$ ), close to the feeding ratio of the Pd and $\mathrm{Cu}$ salt precursors. Taken together, Cu UPD and galvanic replacement play an important role in the formation of PdCu nanodendrites with a $\mathrm{Pd} / \mathrm{Cu}$ atomic ratio close to 1 .

In addition to $\mathrm{Cu}$ UPD and galvanic replacement, the type of reducing agent used, with different reducing power, is also of great importance to the formation of PdCu nanodendrites. In the absence of $\mathrm{W}(\mathrm{CO})_{6}$ (Fig. $\left.5 \mathrm{~A}\right)$, nanoparticles with a polyhedral shape instead of a dendritic structures are generated, with benzyl alcohol as a mild reducing agent. When replacing $\mathrm{W}(\mathrm{CO})_{6}$ with citric acid (Fig. 5B), the products are also dominated by polyhedra. In this case, benzyl alcohol still acts as a reducing agent in the presence of citric acid, due to the stronger reducing power of benzyl alcohol compared to citric acid. When introducing ascorbic acid as a reducing agent (Fig. 5C), two kinds of irregular particles co-exist in the final product. Similarly, when using $\mathrm{Co}_{2}(\mathrm{CO})_{8}$ instead of $\mathrm{W}(\mathrm{CO})_{6}$ (Fig. 5D), a large number of small particles are obtained, since the overly strong reducing activity of cobalt carbonyl results in rapid and substantial nucleation. These results indicate that the use of $\mathrm{W}(\mathrm{CO})_{6}$ as a reducing agent is indispensable for the formation of $\mathrm{PdCu}$ nanodendrites. It is well-known that $\mathrm{W}(\mathrm{CO})_{6}$ is easily decomposed into $\mathrm{W}$ and $\mathrm{CO}$ at a relatively elevated temperature and then the in situ generated $\mathrm{W}$ acts as a reducing. agent for the shape-controlled synthesis of noble-metal

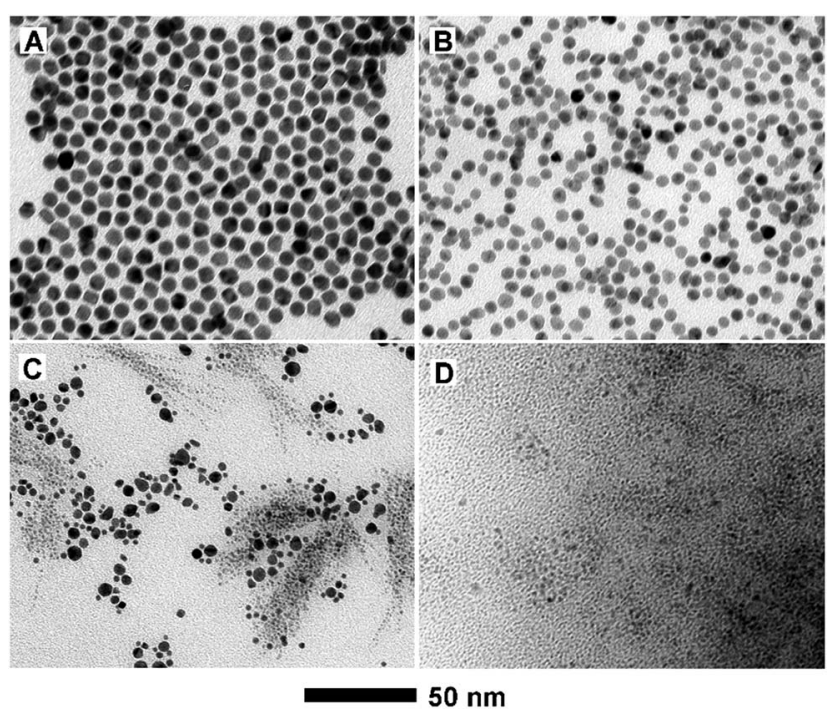

Fig. 5 TEM images of products prepared using the standard procedure, except for the use of different reducing agents: $(A)$ in the absence of $\mathrm{W}(\mathrm{CO})_{6}$, (B) replacing $\mathrm{W}(\mathrm{CO})_{6}$ with citric acid, (C) replacing $\mathrm{W}(\mathrm{CO})_{6}$ with ascorbic acid, and (D) replacing $\mathrm{W}(\mathrm{CO})_{6}$ with $\mathrm{CO}_{2}(\mathrm{CO})_{8}$. 
nanocrystals. ${ }^{46}$ The essence of the issue is the reasonable control of the reduction rate of $\mathrm{Pd}^{2+}$ and $\mathrm{Cu}^{2+}$ ions.

The as-prepared $\mathrm{PdCu}$ alloy nanocrystals with different components were separately loaded on carbon black support (Vulcan XC-72) and then evaluated as electrocatalysts for the MOR with commercial Pd/C serving as the benchmark. Fig. S2 $\uparrow$ shows cyclic voltammograms (CV) from these six catalysts recorded in Ar-purged $0.1 \mathrm{M} \mathrm{KOH}$ aqueous solution. The potential region from 0.1 to $0.4 \mathrm{~V}$ was attributed to the $\mathrm{H}-$ desorption/absorption process. However, there were no obvious $\mathrm{H}$-desorption peaks for most catalysts that were similar to other literature reports previously. ${ }^{31,34,35}$ The peaks at around $0.65 \mathrm{~V}$ and $0.92 \mathrm{~V}$ correspond to the oxidation of $\mathrm{Cu}$ and $\mathrm{Pd}$, respectively. It is generally known that the electrochemically active surface areas (ECSAs) are calculated by integrating the electric charge associated with the hydrogen absorption area. ${ }^{47}$ As summarized in Table S1, $\uparrow$ the ECSAs (normalized to Pd) of $\mathrm{Pd}_{77} \mathrm{Cu}_{23}, \mathrm{Pd}_{65} \mathrm{Cu}_{35}, \mathrm{Pd}_{48} \mathrm{Cu}_{52}, \mathrm{Pd}_{43} \mathrm{Cu}_{57}$ and $\mathrm{Pd}_{35} \mathrm{Cu}_{65}$ supported on carbon are about 23.12, 34.16, 40.49, 23.89 and 24.82 $\mathrm{m}^{2} \mathrm{~g}^{-1}$, respectively, most of which are a little lower than for commercial $\mathrm{Pd} / \mathrm{C}\left(33.0 \mathrm{~m}^{2} \mathrm{~g}^{-1}\right)$, probably due somewhat to aggregation during the preparation of the catalysts, and organic species (e.g., PVP and benzyl alcohol) deposited on their surfaces during synthesis. ${ }^{34,48}$ These $\mathrm{PdCu}$ catalysts were washed several times and treated with tert-butylamine and $\mathrm{NaBH}_{4}$ to remove residual capping agent, however a few bands associated with these species are still visible (see the Fourier transform infrared spectroscopy spectra in Fig. S3†).

The electrocatalytic properties of the $\mathrm{PdCu}$ alloy nanodendrites toward the MOR were measured in $150 \mathrm{~mL}$ of solution containing $0.1 \mathrm{M} \mathrm{KOH}$ and $0.5 \mathrm{M} \mathrm{CH}_{3} \mathrm{OH}$ at a sweep rate of $50 \mathrm{mV} \mathrm{s}^{-1}$ and were compared with those of commercial Pd/C catalysts (Fig. 6). As observed in Fig. 6A and C, all of the $\mathrm{PdCu}$ alloy catalysts show improved specific activity and mass activity relative to commercial $\mathrm{Pd} / \mathrm{C}$, indicating that the incorporation of $\mathrm{Cu}$ into $\mathrm{Pd}$ can enhance the MOR properties. Among these, the $\mathrm{Pd}_{35} \mathrm{Cu}_{65}$ alloy nanodendrites exhibit the highest specific activity $\left(0.540 \mathrm{~mA} \mathrm{~cm}{ }^{-2}\right)$ and mass activity $\left(0.135{\mathrm{~mA} \mu \mathrm{g}_{\mathrm{Pd}}}^{-1}\right)$ at the forward-peak potential (Fig. 6C and D), 9.3 and 7.6 times higher than that of commercial $\mathrm{Pd} / \mathrm{C}$, respectively. For a better understanding of the activity of our own catalysts, a comparison with other typical $\mathrm{PdCu}$ and $\mathrm{Pd} / \mathrm{C}$ catalysts is summarized in Table S2. $\dagger$ We find that the enhancement factor (with commercial $\mathrm{Pd} / \mathrm{C}$ as a reference) of our $\mathrm{Pd}_{35} \mathrm{Cu}_{65}$ alloy nanodendrites ranked at the forefront, owing to the unique dendritic structure relative to other typical examples in the literatures. ${ }^{49-54}$

The long-term performance of $\mathrm{PdCu}$ alloy nanodendrites and $\mathrm{Pd} / \mathrm{C}$ towards the MOR was evaluated in $0.1 \mathrm{M} \mathrm{KOH}$ and $0.5 \mathrm{M} \mathrm{CH}_{3} \mathrm{OH}$ for $3000 \mathrm{~s}$ (Fig. 7). The current (normalized using Pd mass) obtained with the PdCu catalysts and commercial Pd/ $\mathrm{C}$ decreased drastically due to adsorption of intermediates (e.g., $\mathrm{CO})$ on the surfaces, as reported in the literature. ${ }^{55}$ After $1000 \mathrm{~s}$, the currents decayed at a very slow rate and approached the limiting current at $3000 \mathrm{~s}$ (Fig. 7B). The limiting currents of the $\mathrm{PdCu}$ alloy nanodendrites are higher than for commercial Pd/C. The $\mathrm{Pd}_{35} \mathrm{Cu}_{65}$ catalyst exhibited the highest current in the entire
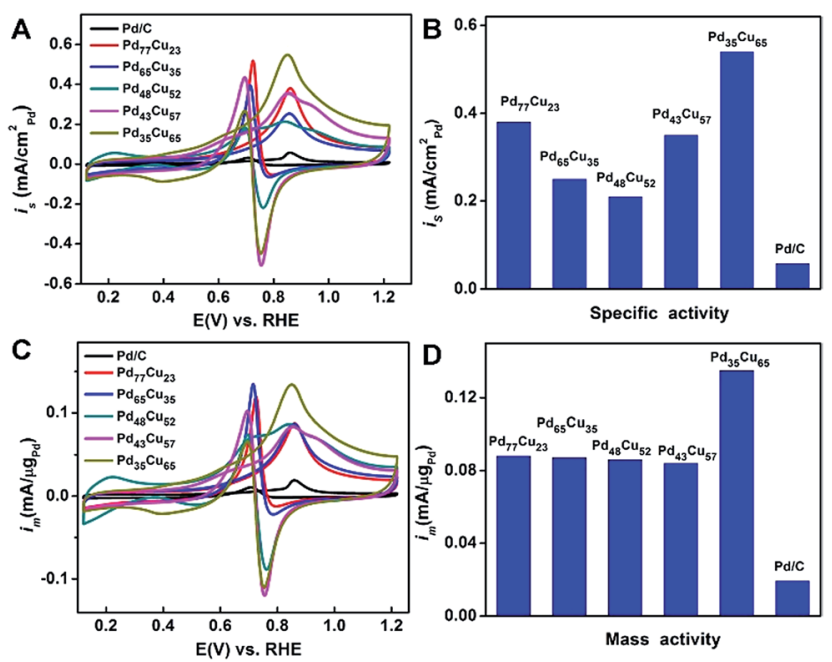

Fig. 6 (A) Cyclic voltammograms normalized using surface area, (B) specific activity at the forward-peak potential, (C) cyclic voltammograms normalized using Pd mass, and (D) mass activity at the forwardpeak potential of the five $\mathrm{PdCu} / \mathrm{C}$ catalysts with different compositions including commercial $\mathrm{Pd} / \mathrm{C}$. The electro-oxidation of methanol was performed in Ar-saturated aqueous solution containing $0.1 \mathrm{M} \mathrm{KOH} /$ $0.5 \mathrm{M} \mathrm{CH}_{3} \mathrm{OH}$ at a sweep rate of $50 \mathrm{mV} \mathrm{s}^{-1}$.

test time, implying that superior stability originates from a high $\mathrm{Cu}$ content, which could accelerate the oxidation of $\mathrm{CO}_{\mathrm{ads}}{ }^{50,56}$

The enhanced performances of the $\mathrm{PdCu}$ alloy catalysts in the MOR can be attributed to a combination of a bifunctional mechanism and the unique dendritic structures. ${ }^{39,57}$ In methanol electro-oxidation, reaction intermediates mainly containing $\mathrm{CO}_{\text {ads }}$ are inevitably generated, which severely poison the active sites by strongly adsorbing on the surface of the Pd sites. ${ }^{55}$ The $\mathrm{Cu}$ component in the alloy can accelerate the oxidation of reaction intermediates, especially $\mathrm{CO}_{\mathrm{ads}}$, since $\mathrm{Cu}$ is more active than Pd for CO oxidation..$^{56}$ As such, this bifunctional effect can remove $\mathrm{CO}_{\mathrm{ads}}$ intermediates on the Pd sites, which substantially enhances the catalytic properties of $\mathrm{PdCu}$ alloy catalysts towards the MOR. In addition, the unique dendritic structures, generally containing some high-index facets and defects, also play an important role in enhancing the catalytic properties towards the MOR. ${ }^{43}$
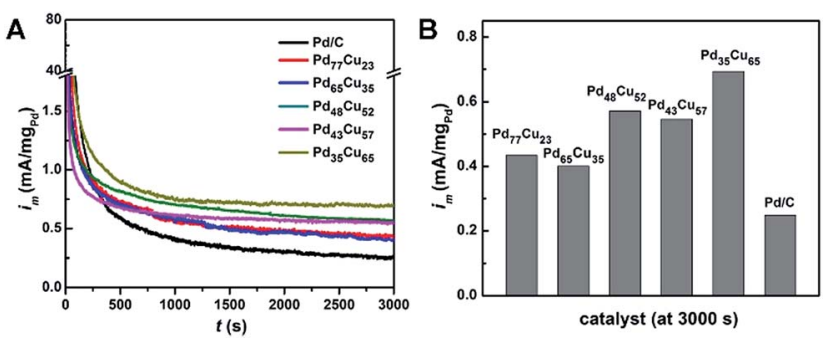

Fig. 7 (A) Chronoamperometric measurements of $\mathrm{PdCu} / \mathrm{C}$ catalysts with different compositions including commercial $\mathrm{Pd} / \mathrm{C}$ in $\mathrm{Ar}$-saturated aqueous solution containing $0.1 \mathrm{M} \mathrm{KOH} / 0.5 \mathrm{M} \mathrm{CH}{ }_{3} \mathrm{OH}$ at a sweep rate of $50 \mathrm{mV} \mathrm{s}^{-1}$. (B) Current normalized using $\mathrm{Pd}$ mass at $3000 \mathrm{~s}$. 


\section{Conclusions}

In summary, PdCu alloy nanodendrites with tunable composition have been synthesized through the co-reduction of $\mathrm{Pd}$ and $\mathrm{Cu}$ salt precursors at different molar ratios using $\mathrm{W}(\mathrm{CO})_{6}$ as a strong reducing agent. We found that high supersaturation during the reaction, arising from the strong reducing agent, and galvanic replacement between the $\mathrm{Cu}$ rich alloy and $\mathrm{Pd}$ precursor might play key roles in facilitating the formation of such nanodendrites. In addition, electrochemical measurements indicate that the $\mathrm{Pd}_{35} \mathrm{Cu}_{65}$ alloy nanodendrites exhibit substantially enhanced catalytic properties in terms of specific and mass activities, relative to such nanodendrites with other compositions as well as commercial $\mathrm{Pd} / \mathrm{C}$, due to their unique structures and possible synergistic effects between these two metals. This work not only reports a facile approach for the synthesis of bimetallic alloy nanodendrites, but also provides an effective strategy to synthesize non-Pt MOR catalysts with enhanced catalytic performance.

\section{Acknowledgements}

The work on electron microscopy was carried out in the Center for Electron Microscopy of Zhejiang University. We acknowledge financial support by the National Science Foundation of China (51372222 and 51522103), the National Program for Support of Top-notch Young Professionals, the Fundamental Research Funds for the Central Universities (2015XZZX004-23), the Program for Innovative Research Teams in University of the Ministry of Education of China (IRT13R54), the thousand talents program for distinguished young scholars (JBW) from the National Science Foundation of China, and a start-up fund (JBW) from Shanghai Jiao Tong University.

\section{Notes and references}

1 B. Steele and A. Heinzel, Nature, 2001, 414, 345-352.

2 M. Debe, Nature, 2012, 486, 43-51.

3 M. Winter and R. Brodd, Chem. Rev., 2004, 104, 4245-4270.

4 M. Scofield, H. Liu and S. Wong, Chem. Soc. Rev., 2015, 44, 5836-5860.

5 S. Kamarudin, W. Daud, S. Ho and U. Hasran, J. Power Sources, 2007, 163, 743-754.

6 C. Bianchini and P. Shen, Chem. Rev., 2009, 109, 4183-4206.

7 X. Zhao, M. Yin, L. Ma, L. Liang, C. Liu, J. Liao, T. Lu and W. Xing, Energy Environ. Sci., 2011, 4, 2736-2753.

8 J. Kua and W. Goddard III, J. Am. Chem. Soc., 1999, 121, 10928-10941.

9 N. Kakati, J. Maiti, S. Lee, S. Jee, B. Viswanathan and Y. Yoon, Chem. Rev., 2014, 114, 12397-12429.

10 H. Zhang, M. Jin and Y. Xia, Chem. Soc. Rev., 2012, 41, 80358049.

11 Y. Jia, Y. Jiang, J. Zhang, L. Zhang, Q. Chen, Z. Xie and L. Zheng, J. Am. Chem. Soc., 2014, 136, 3748-3751.

12 T. Takeguchi, T. Yamanaka, K. Asakura, E. Muhamad, K. Uosaki and W. Ueda, J. Am. Chem. Soc., 2012, 134, 14508-14512.
13 S. Maksimuk, S. Yang, Z. Peng and H. Yang, J. Am. Chem. Soc., 2007, 129, 8684-8685.

14 J. Wu, J. Zhang, Z. Peng, S. Yang, F. Wagner and H. Yang, J. Am. Chem. Soc., 2010, 132, 4984-4985.

15 S. Guo, S. Zhang, X. Sun and S. Sun, J. Am. Chem. Soc., 2011, 133, 15354-15357.

16 J. Wu, L. Qi, H. You, A. Gross, J. Li and H. Yang, J. Am. Chem. Soc., 2012, 134, 11880-11883.

17 B. Xia, H. Wu, X. Wang and X. Lou, J. Am. Chem. Soc., 2012, 134, 13934-13937.

18 J. Rossmeisl, P. Ferrin, G. Tritsaris, A. Nilekar, S. Koh, S. Bae, S. Brankovic, P. Strasser and M. Mavrikakis, Energy Environ. Sci., 2012, 5, 8335-8342.

19 Y. Qi, T. Bian, S. Choi, Y. Jiang, C. Jin, M. Fu, H. Zhang and D. Yang, Chem. Commun., 2014, 50, 560-562.

20 T. Bian, H. Zhang, Y. Jiang, C. Jin, J. Wu, H. Yang and D. Yang, Nano Lett., 2015, 15, 7808-7815.

21 E. Antolini, Energy Environ. Sci., 2009, 2, 915-931.

22 F. Liao, T. Lo and S. Tsang, ChemCatChem, 2015, 7, 19982014.

23 A. Chen and C. Osrtom, Chem. Rev., 2015, 115, 11990-12044. 24 L. Fei, S. Zhong and A. Xu, Angew. Chem., Int. Ed., 2013, 52, 645-649.

25 S. Fu, C. Zhu, D. Du and Y. Lin, ACS Appl. Mater. Interfaces, 2015, 7, 13842-13848.

26 M. Wang, W. Zhang, J. Wang, D. Wexler, S. Poynton, R. Slade, H. Liu, B. Jensen, R. Kerr, D. Shi and J. Chen, ACS Appl. Mater. Interfaces, 2013, 5, 12708-12715.

27 V. Mazumder, M. Chi, M. Mankin, Y. Liu, O. Metin, D. Sun, K. More and S. Sun, Nano Lett., 2012, 12, 1102-1106.

28 Y. Zheng, S. Zhao, S. Liu, H. Yin, Y. Chen, J. Bao, M. Han and Z. Dai, ACS Appl. Mater. Interfaces, 2015, 7, 5347-5357.

29 L. Yang, C. Hu, J. Wang, Z. Yang, Y. Guo, Z. Bai and K. Wang, Chem. Commun., 2011, 47, 8581-8583.

30 L. Zhang, F. Hou and Y. Tan, Chem. Commun., 2012, 48, 7152-7154.

31 Z. Yin, W. Zhou, Y. Gao, D. Ma, C. Kiely and X. Bao, Chem.Eur. J., 2012, 18, 4887-4893.

32 C. Hu, Y. Guo, J. Wang, L. Yang, Z. Yang, Z. Bai, J. Zeng, K. Wang and K. Jiang, ACS Appl. Mater. Interfaces, 2012, 4, 4461-4464.

33 Z. Shih, C. Wang, G. Xu and H. Chang, J. Mater. Chem. A, 2013, 1, 4773-4778.

34 P. Xi, Y. Cao, F. Yang, C. Ma, F. Chen, S. Yu, S. Wang, Z. Zeng and X. Zhang, Nanoscale, 2013, 5, 6124-6130.

35 Q. Gao, Y. Ju, D. An, M. Gao, C. Cui, J. Liu, H. Cong and S. Yu, ChemSusChem, 2013, 6, 1878-1882.

36 L. Zhang, S. Choi, J. Tao, H. Peng, S. Xie, Y. Zhu, Z. Xie and Y. Xia, Adv. Funct. Mater., 2014, 24, 7520-7529.

37 Z. Zhang, J. Huang, L. Zhang, M. Sun, Y. Wang, Y. Lin and J. Zeng, Nanotechnology, 2014, 25, 435602.

38 L. Zhang, H. Su, M. Sun, Y. Wang, W. Wu, T. Yu and J. Zeng, Nano Res., 2015, 8, 2415-2430.

39 B. Lim and Y. Xia, Angew. Chem., Int. Ed., 2011, 50, 76-85.

40 L. Wang, Y. Nemoto and Y. Yamauchi, J. Am. Chem. Soc., 2011, 133, 9674-9677. 
41 A. Mohanty, N. Garg and R. Jin, Angew. Chem., Int. Ed., 2010, 49, 4962-4966.

42 B. Lim, M. Jiang, P. Camargo, E. Cho, J. Tao, X. Lu, Y. Zhu and Y. Xia, Science, 2009, 324, 1302-1305.

43 Y. Qi, J. Wu, H. Zhang, Y. Jiang, C. Jin, M. Fu, H. Yang and D. Yang, Nanoscale, 2014, 6, 7012-7018.

44 Y. Jiang, T. Bian, F. Lin, H. Zhang, C. Jin, Z. Li, D. Yang and Z. Zhang, J. Mater. Chem. A, 2015, 3, 21284-21289.

45 L. Xiong, Y. Huang, X. Liu, G. Sheng, W. Li and H. Yu, Electrochim. Acta, 2013, 89, 24-28.

46 J. Zhang and J. Fang, J. Am. Chem. Soc., 2009, 131, 1854318547.

47 L. Yang, D. Yan, C. Liu, H. Song, Y. Tang, S. Luo and M. Liu, J. Power Sources, 2015, 278, 725-732.

48 Z. Lin, W. Chen, Y. Jiang, T. Bian, H. Zhang, J. Wu, Y. Wang and D. Yang, Nanoscale, 2016, 8, 12812-12818.
49 H. Mao, T. Huang and A. Yu, Electrochim. Acta, 2015, 174, 17.

50 S. Arulmani, S. Krishnamoorthy, J. J. Wu and S. Anandan, Electroanalysis, 2016, 28, 1-9.

51 M. Hsieh and T. Whang, Appl. Surf. Sci., 2013, 270, 252-259. 52 Z. Yin, H. Zheng, D. Ma and X. Bao, J. Phys. Chem. C, 2009, 113, 1001-1005.

53 Z. Li, H. Gong, T. Mu and Y. Luan, CrystEngComm, 2014, 16, 4038-4044.

54 X. Zhou, Y. Gan, Z. Dai and R. Zhang, J. Electroanal. Chem., 2012, 685, 97-102.

55 C. Bianchini and P. Shen, Chem. Rev., 2009, 109, 4183-4206.

56 K. Choi and M. Vannice, J. Catal., 1991, 131, 22-35.

57 H. Gasteiger, N. Markovic, P. Ross and E. Cairns, J. Phys. Chem., 1993, 97, 12020-12029. 